\title{
Fifteen years of experience with ATS mechanical heart valve prostheses
}

\author{
Akira Sezai, MD, ${ }^{\mathrm{a}}$ Mitsumasa Hata, MD, ${ }^{\mathrm{a}}$ Tetsuya Niino, MD, ${ }^{\mathrm{a}}$ Isamu Yoshitake, MD, ${ }^{\mathrm{a}}$ \\ Yuji Kasamaki, MD, ${ }^{\mathrm{b}}$ Atsushi Hirayama, MD, ${ }^{\mathrm{b}}$ and Kazutomo Minami, MD ${ }^{\mathrm{a}}$
}

\begin{abstract}
Background: ATS Medical, Inc, developed a mechanical heart valve that has been in use since 1992. In this article, we present the results of 15 years of follow-up of patients who have undergone ATS heart valve replacement at our hospital.
\end{abstract}

\begin{abstract}
Methods and Results: We performed ATS heart valve replacements on 231 patients between September 1993 and March 2008. Our operative mortality rate for the study period was $2.2 \%$. The survival for postoperative thromboembolic events was $0.29 \% / \mathrm{pt}$-y for aortic valve replacement, $0.48 \% / \mathrm{pt}$-y for mitral, $0.80 \% / \mathrm{pt}$-y for double valve replacement, and overall $0.44 \% / \mathrm{pt}-\mathrm{y}$. The survival after bleeding events was $0.29 \% / \mathrm{pt}-\mathrm{y}$ for aortic valve replacement, $0.16 \% / \mathrm{pt}$-y for mitral, $0 \% / \mathrm{pt}$-y for double valve replacement, and overall $0.19 \% / \mathrm{pt}-\mathrm{y}$. Patient-prosthesis mismatch, as determined by echocardiography, was found in $83.3 \%$ of patients at $19 \mathrm{~mm}$, but other sizes showed good valve function. Prosthetic valve noise was undetectable in $92.8 \%$ of patients, and quality of life was excellent.
\end{abstract}

Conclusions: Few prosthetic valve-related complications were seen with ATS heart valve replacements in this study, and the follow-up results were favorable. The international normalized ratio was maintained in the range 1.6 to 2.0 in patients with aortic valve replacement in sinus rhythm. Not only bleeding events, seen at a rate of $0.19 \% / \mathrm{pt}-\mathrm{y}$, but also thromboembolic events, at $0.44 \% / \mathrm{pt}-\mathrm{y}$, were low when compared with conventional mechanical valves. Prosthetic valve noise is low, and this appears to be an excellent mechanical valve from the quality of life standpoint. The ATS valve has an excellent safety profile when compared with other mechanical valves. (J Thorac Cardiovasc Surg 2010;139:1494-500)

The ATS valve (ATS Medical, Inc, Minneapolis, Minn) has an expanded valve orifice area, inasmuch as the entire orifice is made of pyrolytic carbon material, with increased durability. It has a superior safety profile, in terms of antithrombotic and hemolytic effects, in comparison with conventional prosthetic valves. It was developed as a bileaflet valve and is used around the world. ${ }^{1,2}$ The first bileaflet valve to be developed was the St Jude Medical (SJM) valve, which was released in 1977 (St Jude Medical Inc, St Paul, Minn). It has excellent hemodynamics with central flow, and good follow-up results made it the highest-rated mechanical valve in the world..$^{3-5}$ At our hospital, we have used the SJM valve since 1978, when it was implanted in the first Japanese patient, and we have achieved reliable results. ${ }^{6,7}$ Over an observation period of more than 10 years, thromboembolic events have been reported to occur at a rate of $0.20 \%$ to $3.5 \% / \mathrm{pt}-\mathrm{y}$, valve thrombosis at $0.06 \%$ to $0.18 \% / \mathrm{pt}-\mathrm{y}$, and

\footnotetext{
From the Departments of Cardiovascular Surgery ${ }^{\mathrm{a}}$ and Cardiology, ${ }^{\mathrm{b}}$ Nihon University School of Medicine, Tokyo, Japan.

This study was supported by an Osawa Research grant from Nihon University.

Disclosures: None.

Received for publication April 14, 2009; revisions received June 17, 2009; accepted for publication July 16, 2009; available ahead of print Sept 11, 2009.

Address for reprint: Akira Sezai, MD, the Department of Cardiovascular Surgery,

Nihon University School of Medicine, 30-1 Oyaguchi-kamimachi Itabashi-ku,

Tokyo, 173-8610, Japan (E-mail: asezai@med.nihon-u.ac.jp).

$0022-5223 / \$ 36.00$

Copyright (c) 2010 by The American Association for Thoracic Surgery doi:10.1016/j.jtcvs.2009.07.039
}

bleeding events at $0.45 \%$ to $3.5 \% / \mathrm{pt}-\mathrm{y}$, but the results vary among institutions. ${ }^{4-9}$

The ATS mechanical heart valve was first used in valve replacement surgery in May 1992, and its first use in Japan was at our hospital in September 1993. It was licensed by the Ministry of Health, Labour and Welfare in July 1996 and came into general use thereafter. There have been several case reports concerning this valve, confirming its usefulness, but few reports on follow-up results. In this article, we present the results of 15 years' follow-up with the ATS valve at our hospital.

\section{PATIENTS AND METHODS Patient Population}

Between September 1993 and March 2008, 238 patients underwent valve replacement with the ATS valve at the Nihon University Itabashi Hospital, and we were able to follow up 231 of these patients, excluding those who underwent tricuspid valve replacements. At our hospital, the valve of choice was the SJM valve from 1978 and the ATS valve from 1993. Since 2006 , both valves have been used in tandem. Mechanical valves are generally used only for patients less than 70 years of age at our hospital. However, when a patient is more than 70 years old and a $19-\mathrm{mm}$ bioprosthetic valve cannot be implanted, a mechanical valve is selected when it is judged that the patient should have an $18-\mathrm{mm}$ or smaller valve for better quality of life (QOL) in consideration of his/her general preoperative condition, rather than undergoing aortic root enlargement to allow implantation of a bioprosthetic valve. This study was approved by the Ethics Committee of Nihon University Itbashi Hospital and was registered with the University Hospital Medical Information Network (Study No. ID: 000001636). Final examinations were conducted in February 2009. The age of the patients ranged from 14 to 83 years (mean $57.3 \pm 11.6$ years), including $19(8.3 \%)$ patients who 


\author{
Abbreviations and Acronyms \\ $\mathrm{AP}=$ advanced performance \\ $\mathrm{AVR}=$ aortic valve replacement \\ $\mathrm{DVR}=$ double valve replacement $(\mathrm{AVR}+\mathrm{MVR})$ \\ $\mathrm{LDH}=$ lactic acid dehydrogenase \\ MVR $=$ mitral valve replacement \\ PPM $=$ prosthesis-patient mismatch \\ $\mathrm{PVL}=$ paravalvular leakage \\ $\mathrm{QOL}=$ quality of life \\ $\mathrm{SJM}=$ St Jude Medical
}

TABLE 1. Preoperative data

\begin{tabular}{lccc}
\hline & AVR & MVR & DVR \\
\hline No. & 103 & 92 & 36 \\
Age (y) & $57.7 \pm 13.7$ & $56.7 \pm 10.6$ & $57.9 \pm 7.0$ \\
Gender (male/female) & $78: 25$ & $43: 49$ & $22: 14$ \\
Diagnosis & & & \\
Aortic & & & \\
$\quad$ Stenosis & 21 & - & 7 \\
$\quad$ Regurgitation & 60 & - & 13 \\
Combined & 20 & - & 16 \\
$\quad$ Prosthetic valve dysfunction & 2 & - & 0 \\
Mitral & & & \\
$\quad$ Stenosis & - & 20 & 10 \\
Regurgitation & - & 51 & 13 \\
Combined & - & 16 & 13 \\
Prosthetic valve dysfunction & - & 5 & 0 \\
$\quad$ Reoperation & 5 & 13 & 2 \\
NHYA class & & & \\
I & 1 & 0 & 0 \\
II & 23 & 36 & 3 \\
III & 51 & 52 & 20 \\
IV & 18 & 14 & 13 \\
\hline AVR,
\end{tabular}

$A V R$, Isolated aortic valve replacement; $M V R$, isolated mitral valve replacement; $D V R$, double valve replacement; NHYA, New York Heart Association.

following questions were asked: (1) Do you hear a prosthetic valve sound (audible)? For patients who do hear something, (2) do you sometimes hear it (sometimes disturbance)? (3) Does it disturb your daily life (daytime disturbance)? (4) Does it disturb your sleep (sleep disturbance)? (5) If there was a prosthetic valve with no noise, would you want to exchange it for your present valve (prefers less noisy valve)? For part 4, the noise index is an indicator of patient stress caused by prosthetic valve noise that we proposed in an earlier paper. ${ }^{10}$ The level of stress is expressed numerically, with maximum stress assigned 10 points and 0 points when no stress at all is felt.

TABLE 2. Prosthetic valve size and body surface area

\begin{tabular}{lcc}
\hline & Patient numbers & BSA $\left(\mathbf{m}^{2}\right)$ \\
\hline AVR & & \\
$16 \mathrm{~mm} \mathrm{AP}$ & 1 & 1.35 \\
$18 \mathrm{~mm} \mathrm{AP}$ & 15 & $1.43 \pm 0.08$ \\
$19 \mathrm{~mm}$ & 6 & $1.48 \pm 0.19$ \\
$20 \mathrm{~mm} \mathrm{AP}$ & 10 & $1.46 \pm 0.15$ \\
$21 \mathrm{~mm}$ & 25 & $1.54 \pm 0.17$ \\
$22 \mathrm{~mm} \mathrm{AP}$ & 0 & - \\
$23 \mathrm{~mm}$ & 45 & $1.67 \pm 0.17$ \\
$24 \mathrm{~mm} \mathrm{AP}$ & 4 & $1.77 \pm 0.30$ \\
$25 \mathrm{~mm}$ & 17 & $1.74 \pm 0.12$ \\
$27 \mathrm{~mm}$ & 16 & $1.75 \pm 0.13$ \\
MVR & & \\
$23 \mathrm{~mm}$ & 1 & 1.50 \\
$25 \mathrm{~mm}$ & 11 & $1.45 \pm 0.20$ \\
$27 \mathrm{~mm}$ & 58 & $1.53 \pm 0.15$ \\
$29 \mathrm{~mm}$ & 46 & $1.62 \pm 0.20$ \\
$31 \mathrm{~mm}$ & 12 & $1.65 \pm 0.27$ \\
\hline
\end{tabular}

$A V R$, Aortic valve replacement; $A P$, advanced performance; $B S A$, body surface area; $M V R$, mitral valve replacement.

to 12 months postoperatively, using transthoracic echocardiography. cialists in echocardiography performed all examinations. For MVR procedures, the continuous Doppler wave method was used to measure peak velocity and mean velocity in the left ventricular inflow region. The peak and mean pressure gradients were calculated by the simplified Bernoulli formula. For AVR procedures, the continuous Doppler wave method was used to measure peak velocity and mean velocity in the aortic valve distal region, from which the peak and mean pressure gradients were calculated. The effective orifice area of the artificial valve was calculated from the pressure half-time for the mitral valve and from the modified continuity equation for the aortic valve. The effective orifice area was divided by the body surface area, and the effective orifice area index was calculated. For the aortic valve, the effective orifice area index showed moderate prosthesis-patient mismatch (PPM) at 0.66 to 0.85 and severe PPM at less than 0.65 . Measured values were all the average over 10 consecutive heartbeats.

\section{Hemolysis}

Serum lactic acid dehydrogenase (LDH) and haptoglobin levels were measured at 6 months postoperatively as indices of postoperative hemolysis. Deaths, including operative deaths within 6 months postoperatively, and patients with paravalvular leakage (PVL) confirmed by echocardiography, and patients with previous surgery were excluded. None of the patients had undergone blood transfusion within 1 month and none of them had diseases that could increase LDH (such as gallstones) at 6 months after surgery.

\section{Evaluation of Prosthetic Valve Noise}

Patients were interviewed regarding prosthetic valve noise at 6 months postoperatively. Early deaths and deaf patients were excluded. The 


\section{Follow-up}

Postoperative anticoagulant therapy or antiplatelet therapy comprised warfarin, aspirin ( $100 \mathrm{mg} /$ day $)$, or dipyridamole $(200 \mathrm{mg} /$ day $)$. The international normalized ratio was maintained at 1.6 to 2.0 in AVR patients, 1.8 to 2.5 in MVR patients, and 2.0 to 2.5 in DVR patients, patients with atrial fibrillation, and patients with a left atrial diameter of $50 \mathrm{~mm}$ or more.

Postoperatively, patients were seen once a month as outpatients. Postoperative event evaluations were based on the valvulopathy postoperative evaluation guidelines of The American Association for Thoracic Surgery, the European Association for Thoracic Surgery, and the Society of Thoracic Surgeons. ${ }^{11}$

\section{Statistical Analysis}

The actuarial survival and postoperative complication-free rate were evaluated by the Kaplan-Meier method, and differences between groups were assessed by the log-rank test. Numerical values were expressed as mean \pm standard deviations.

\section{RESULTS \\ Follow-up}

Follow-up was not possible for 2 patients, yielding a follow-up rate of $99.1 \%$. The average follow-up period was $6.93 \pm 3.77$ years, the longest being 15.3 years. A total of 1601.7 patient-years were performed.

Early mortality and causes of death. There were 5 deaths within 30 days postoperatively (2.2\%): 2 after AVR (1.9\%), 1 after MVR $(1.1 \%)$, and 2 after DVR (5.6\%). There were 5 deaths within 60 days postoperatively (2.2\%): 2 after AVR (1.9\%), 1 after MVR (1.1\%), and 2 after DVR (5.6\%). There were 5 deaths within 90 days postoperatively (2.2\%): 2 after AVR (1.9\%), 1 after MVR (1.1\%), and 2 after DVR $(5.6 \%)$. All early deaths occurred in the hospital. The cause of death was low cardiac output syndrome in 3 cases and acute renal failure, acute heart failure, cerebral hemorrhage, and graft-versus-host disease in 1 case each. After detection of complications, patients underwent transesophageal or transthoracic echocardiography. Since PVL was detected in the patient who eventually died of graft-versus-host disease, the operation was repeated. Autopsies were performed on 2 patients who died of low output syndrome, as well as those who died of acute heart failure, cerebral hemorrhage, and graft-versus-host disease (autopsy rate: $71.4 \%$ ). No prosthetic valve-related complications, such as PVL, were found at autopsy.

Late mortality and causes of death. There were 25 deaths, including 12 after AVR, 10 after MVR, and 3 after DVR. The cause of death was malignant disease in 8 patients, heart failure in 6, sudden death, arrhythmia, and acute renal failure in 2 each, and cerebral infarction, miliary tuberculosis, septicemia, pneumonia, and thoracic aortic rupture in 1 each. Autopsies were performed in the 2 sudden deaths, 2 patients who died of arrhythmia, and 1 each of miliary tuberculosis, septicemia, pneumonia, and thoracic aortic rupture (autopsy rate: $32 \%$ ). No abnormal findings related to the prosthetic valves were found at autopsy. The other patients underwent transesophageal or transthoracic echocardiography, but no prosthetic valve-related complications were found. The cumulative survival, including early mortality, was $91.8 \% \pm 2.8 \%$ at 5 years, $84.8 \% \pm 4.8 \%$ at 10 years, and $59.1 \% \pm 17.9 \%$ at 15 years after AVR; $91.2 \% \pm 3.0 \%$ at 5 years, $89.8 \% \pm 3.3 \%$ at 10 years, and $76.9 \% \pm 12.2 \%$ at 15 years after MVR; and $83.3 \%$ $\pm 6.2 \%$ at 5 years, $79.7 \% \pm 6.9 \%$ at 10 years, and $79.7 \% \pm 6.9 \%$ at 15 years after DVR (Figure 1).

Valve-related mortality. Cerebral hemorrhage occurred in 1 patient, and PVL occurred in 1 patient with early mortality owing to graft-versus-host disease, 2 with cerebral infarction, and 2 patients with late mortality owing to sudden death, for a total of $6(2.6 \%)$ patients.

Valve-related complications: Nonstructural dysfunction. PVL occurred in 2 patients apart from the 1 fatal case. One patient underwent reoperation, and the other had an LDH of $721 \mathrm{IU} / \mathrm{L}$ and was observed without another operation. The nonstructural dysfunction-free rate was $100 \%$ at 5 years, $100 \%$ at 10 years, and $100 \%$ at 15 years after AVR; $100 \%$ at 5 years, $100 \%$ at 10 years, and $100 \%$ at 15 years after MVR; and $94.0 \% \pm 4.1 \%$ at 5 years, $89.5 \% \pm 5.9 \%$ at 10 years, and $89.5 \% \pm 5.9 \%$ at 15 years after DVR. The survival was $0 \% / \mathrm{pt}$-y after AVR, $0 \% / \mathrm{pt}-\mathrm{y}$ after MVR, $1.20 \% / p t-y$ after DVR, and $0.19 \% / p t-y$ for all patients.

Thromboembolic disease. In addition to the 1 death owing to cerebral infarction, there were 3 other cases of cerebral infarction, 1 of transient ischemic attack, and 2 of left atrial thrombosis for a total of 7 thromboembolic events. Of the 4 patients having cerebral infarction, 1 died, 2 recovered with no aftereffects, and 1 had lingering paresis. One patient with left atrial thrombosis underwent a second operation, and the blood clot was removed by thrombolysis in the other.

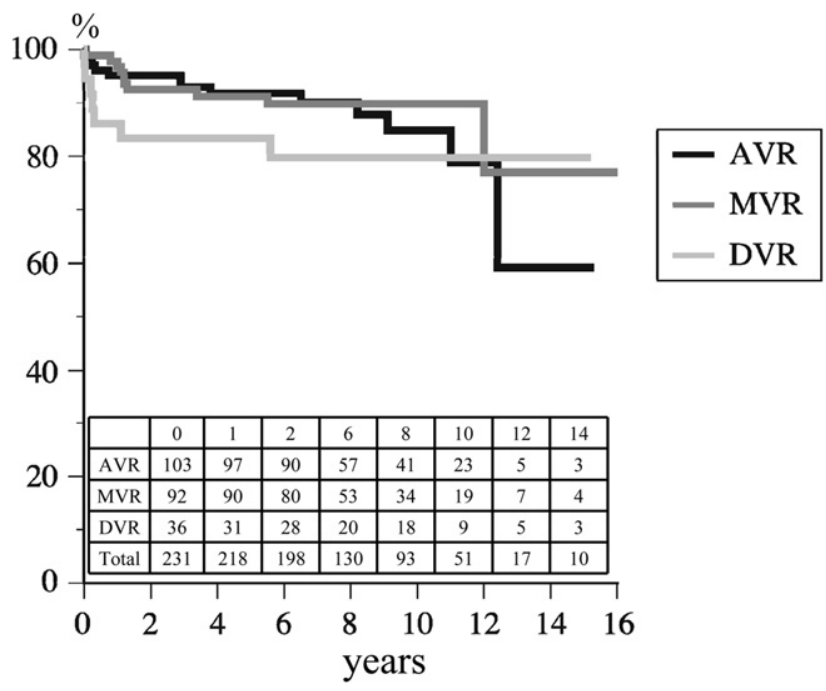

FIGURE 1. Actuarial survival curves. $A V R$, Isolated aortic valve replacement; $M V R$, isolated mitral valve replacement; $D V R$, double valve replacement. 


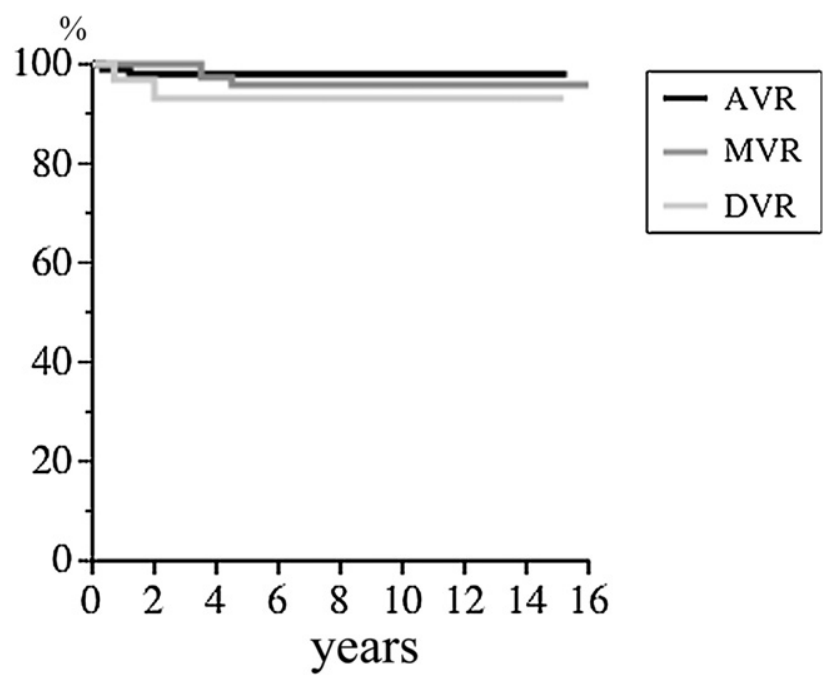

FIGURE 2. Freedom from thromboembolic events. $A V R$, Isolated aortic valve replacement; $M V R$, isolated mitral valve replacement; $D V R$, double valve replacement.

The patient who underwent a second operation was a 32year-old woman. She had undergone MVR with an SJM valve previously, but MVR was repeated because of left atrial thrombosis and PVL. She had a giant left atrium (left atrial diameter: $80 \mathrm{~mm}$ ). After plication, the postoperative left atrial diameter was $70 \mathrm{~mm}$. Inasmuch as a massive thrombus developed in the left atrium at 3 years 5 months postoperatively, thrombectomy was performed. No abnormalities of the ATS valve were found and replacement was not necessary. At present, 7 years have passed since the second operation, but no further thrombus has been detected in the left atrium. The patient who did not undergo an operation was a 71-year-old woman. She had undergone DVR, and a 20-mm thrombus was found in the left atrium by transesophageal echocardiography on day 10 postoperatively. Because the thrombus was small and there were no abnormalities of the ATS valve itself, thrombolysis with tissue plasminogen activator was performed and the thrombus disappeared. At present, 5 years have passed since this procedure and no further thrombi have been detected in the left atrium. In both patients, atrial fibrillation and marked left atrial hypertrophy were observed.

The thromboembolic event-free rate was $98.0 \% \pm 1.4 \%$ at 5 years, $98.0 \% \pm 1.4 \%$ at 10 years, and $98.0 \% \pm 1.4 \%$ at 15 years after AVR; $98.6 \% \pm 1.3 \%$ at 5 years, $98.6 \% \pm$ $1.3 \%$ at 10 years, and $98.6 \% \pm 1.3 \%$ at 15 years after MVR; and $93.3 \% \pm 4.6 \%$ at 5 years, $93.3 \% \pm 4.6 \%$ at 10 years, and $93.3 \% \pm 4.6 \%$ at 15 years after DVR. The survival was $0.29 \% / \mathrm{pt}-\mathrm{y}$ after AVR, $0.48 \% / \mathrm{pt}-\mathrm{y}$ after MVR, $0.80 \% /$ pt-y after DVR, and $0.44 \% /$ pt-y for all patients (Figure 2).

Bleeding events. In addition to 1 early death owing to cerebral hemorrhage, 2 patients had cerebral hemorrhages

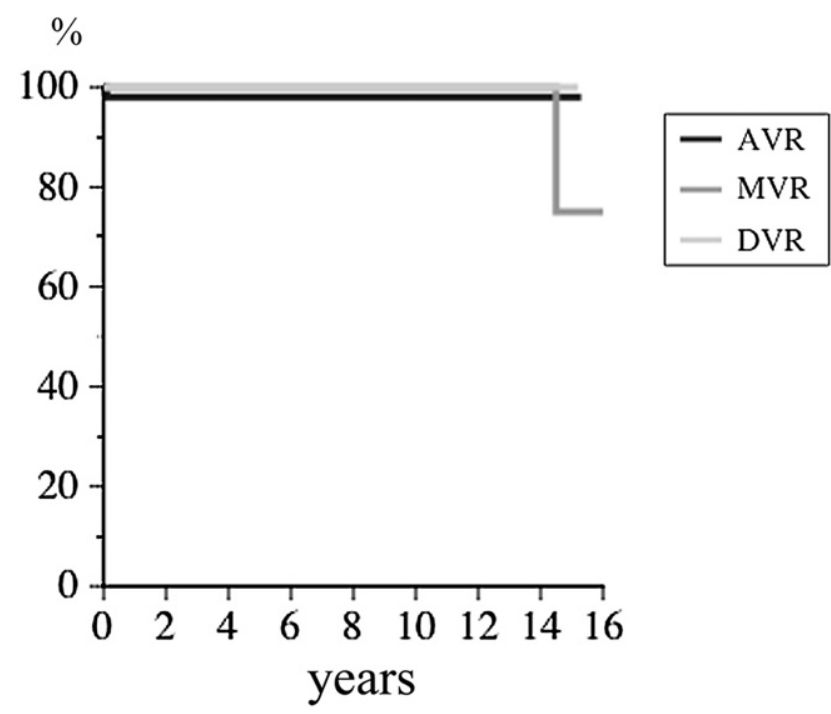

FIGURE 3. Freedom from bleeding events. $A V R$, Isolated aortic valve replacement; $M V R$, isolated mitral valve replacement; $D V R$, double valve replacement.

during the follow-up period for a total of 3 bleeding events. One patient recovered with no aftereffects, and the other had lingering paresis. The bleeding event-free rate was $98.0 \%$ $\pm 1.4 \%$ at 5 years, $98.0 \% \pm 1.4 \%$ at 10 years, and $98.0 \% \pm 1.4 \%$ at 15 years after AVR; $100 \%$ at 5 years, $100 \%$ at 10 years, and $75.0 \% \pm 2.2 \%$ at 15 years after MVR; and $100 \%$ at 5 years, $100 \%$ at 10 years, and $100 \%$ at 15 years after DVR. The survival was $0.29 \% / p t-y$ after AVR, 0.16\%/pt-y after MVR, 0\%/pt-y after DVR, and $0.19 \% / \mathrm{pt}-\mathrm{y}$ for all patients (Figure 3).

Other valve-related complications. No structural valve deterioration, valve thrombosis, or operative valve endocarditis has been observed to date.

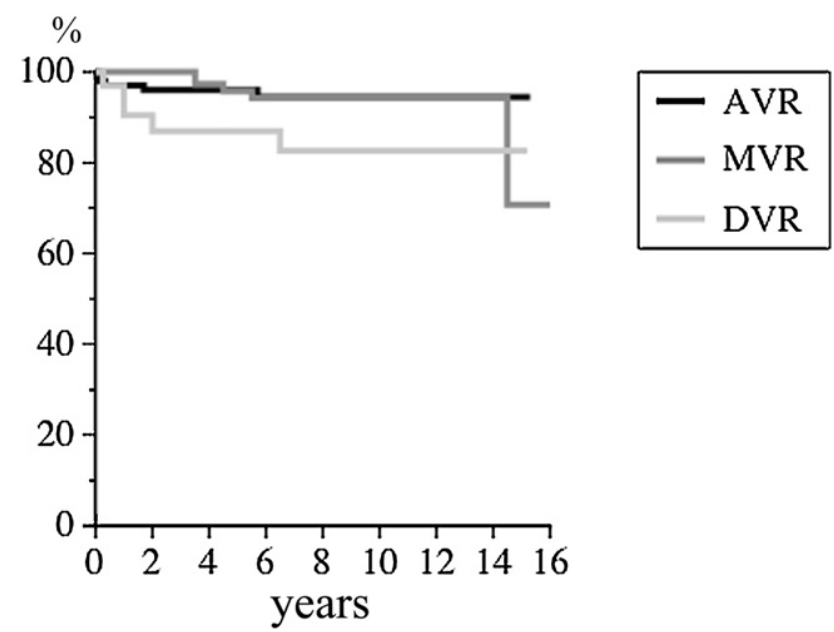

FIGURE 4. Freedom from valve-related complications. $A V R$, Isolated aortic valve replacement; $M V R$, isolated mitral valve replacement; $D V R$, double valve replacement. 
The total valve-related complication-free rate was $96.0 \%$ $\pm 1.9 \%$ at 5 years, $93.0 \% \pm 2.8 \%$ at 10 years, and $93.0 \%$ $\pm 2.8 \%$ at 15 years after AVR; $98.6 \% \pm 1.3 \%$ at 5 years, $97.0 \% \pm 2.1 \%$ at 10 years, and $72.8 \% \pm 21.1 \%$ at 15 years after MVR; and $87.4 \% \pm 5.9 \%$ at 5 years, $83.2 \% \pm 6.9 \%$ at 10 years, and $83.2 \% \pm 6.9 \%$ at 15 years after DVR. The survival was $0.72 \% / \mathrm{pt}-\mathrm{y}$ after AVR, $0.79 \% / \mathrm{pt}-\mathrm{y}$ after MVR, $1.94 \% / p t-y$ after DVR, and $0.95 \% / p t-y$ for all patients (Figure 4).

Echocardiographic results. The results of transthoracic echocardiographic evaluation of prosthetic valve function are shown in Table 3. Moderate PPM was found in 1 $(100 \%)$ patient with a $16-\mathrm{mm}$ AP (advanced performance) valve, in $3(21.4 \%)$ of 14 with $18-\mathrm{mm} \mathrm{AP}$ valves, in 4 $(66.7 \%)$ of 6 with $19-\mathrm{mm}$ valves, in $1(10 \%)$ of 10 with 20 -mm AP valves, in $1(4.2 \%)$ of 24 with 21 -mm valves, in $5(11.1 \%)$ of 45 with $23-\mathrm{mm}$ valves, and in no patients with 24-mm AP, 25-mm, or 27-mm valves. Serious PPM was found in no $16-\mathrm{mm}$ AP or $18-\mathrm{mm}$ AP valves, in 1 $(16.7 \%)$ of $619-\mathrm{mm}$ valves, in no $20-\mathrm{mm}$ AP or $21-\mathrm{mm}$ valves, in $2(4.4 \%)$ of $4523-\mathrm{mm}$ valves, and in no $24-\mathrm{mm}$ $\mathrm{AP}, 25-\mathrm{mm}$, or $27-\mathrm{mm}$ valves.

Hemolysis. LDH values at 6 months postoperatively were $218.3 \pm 42.3 \mathrm{IU} / \mathrm{L}$ (range 154-341 IU/L) after AVR, $247.5 \pm 58.5 \mathrm{IU} / \mathrm{L}(158-442 \mathrm{IU} / \mathrm{L})$ after MVR, and 297.8 $\pm 85.6 \mathrm{IU} / \mathrm{L}(180-596 \mathrm{IU} / \mathrm{L})$ after DVR. Patients falling within the normal range (220 IU/L or less) comprised 63 (63.6\%) after AVR, 38 (41.8\%) after MVR, and 2 (7.1\%) after DVR. Haptoglobin levels stayed within the normal range for all patients.

Prosthetic valve noise survey. A total of $16(7.2 \%)$ patients responded to the questionnaire in the affirmative,

TABLE 3. Postoperative echocardiographic data

\begin{tabular}{ccccc}
\hline & $\begin{array}{c}\text { PPG } \\
(\mathbf{m m} \mathbf{H g})\end{array}$ & $\begin{array}{c}\text { MPG } \\
(\mathbf{m m} \mathbf{H g})\end{array}$ & $\begin{array}{c}\text { EOA } \\
\left(\mathbf{c m}^{\mathbf{2}}\right)\end{array}$ & EOAI \\
\hline Aortic valve & & & & \\
$16 \mathrm{~mm} \mathrm{AP}$ & 30.4 & 16.5 & 1.01 & 0.75 \\
$18 \mathrm{~mm} \mathrm{AP}$ & $22.1 \pm 8.0$ & $10.1 \pm 3.2$ & $1.42 \pm 0.33$ & $0.99 \pm 0.20$ \\
$19 \mathrm{~mm}$ & $38.8 \pm 11.0$ & $18.5 \pm 5.3$ & $1.07 \pm 0.12$ & $0.75 \pm 0.09$ \\
$20 \mathrm{~mm} \mathrm{AP}$ & $19.3 \pm 9.7$ & $9.2 \pm 3.9$ & $1.49 \pm 0.23$ & $1.03 \pm 0.14$ \\
$21 \mathrm{~mm}$ & $23.8 \pm 10.5$ & $10.2 \pm 4.3$ & $1.65 \pm 0.36$ & $1.07 \pm 0.24$ \\
$22 \mathrm{~mm} \mathrm{AP}$ & - & - & - & - \\
$23 \mathrm{~mm}$ & $18.3 \pm 9.5$ & $8.6 \pm 5.5$ & $1.76 \pm 0.46$ & $1.07 \pm 0.28$ \\
$24 \mathrm{~mm} \mathrm{AP}$ & $14.8 \pm 4.2$ & $8.6 \pm 2.4$ & $2.35 \pm 0.37$ & $1.35 \pm 0.23$ \\
$25 \mathrm{~mm}$ & $18.8 \pm 6.9$ & $7.9 \pm 3.5$ & $1.81 \pm 0.34$ & $1.05 \pm 0.21$ \\
$27 \mathrm{~mm}$ & $14.5 \pm 8.5$ & $6.6 \pm 4.1$ & $2.22 \pm 0.31$ & $1.29 \pm 0.19$ \\
Mitral valve & & & & \\
$23 \mathrm{~mm}$ & 12.0 & 6.0 & 3.40 & 2.27 \\
$25 \mathrm{~mm}$ & $8.8 \pm 3.1$ & $3.1 \pm 1.6$ & $2.68 \pm 0.87$ & $1.92 \pm 0.82$ \\
$27 \mathrm{~mm}$ & $7.9 \pm 2.8$ & $3.2 \pm 1.3$ & $2.77 \pm 0.60$ & $1.83 \pm 0.43$ \\
$29 \mathrm{~mm}$ & $7.2 \pm 3.0$ & $3.0 \pm 1.5$ & $3.07 \pm 0.66$ & $1.96 \pm 0.43$ \\
$31 \mathrm{~mm}$ & $7.0 \pm 2.4$ & $2.5 \pm 0.8$ & $3.01 \pm 0.79$ & $1.88 \pm 0.66$ \\
\hline
\end{tabular}

$P P G$, Peak pressure gradient; $M P G$, mean pressure gradient; $E O A$, effective orifice area; $E O A I$, effective orifice area index; $A P$, advanced performance. saying they were aware of prosthetic valve noise, comprising 5 AVR, 5 MVR, and 6 DVR patients. However, all patients responded that they "heard something but did not notice it." Prosthetic valve noise caused sleep disturbances or disturbances in daily living in only a small number of patients. Among 16 patients who were aware of prosthetic valve noise, 6 had undergone an operation in the past (valve replacement in 3 and open mitral commissurotomy in the other 3 ). Among the 3 patients with prior valve replacement, the previous prosthetic valve was an SJM valve in 2 patients and a Starr-Edwards ball valve in 1 patient. All 3 patients considered that the ATS valve was less noisy than their previous mechanical valves.

The mean noise index was $0.22 \pm 0.61$ points ( $0-3$ points) for all patients, $0.12 \pm 0.46$ points ( $0-2$ points) after AVR, $0.25 \pm 0.65$ points ( $0-3$ points) after MVR, and $0.40 \pm 0.70$ points ( $0-3$ points) after DVR.

\section{DISCUSSION}

This study is the first to present results of a 15 -year follow-up for ATS valves. We examined operative results, follow-up results, prosthetic valve-related complications, and echocardiographic evaluation of prosthetic valve function, and the results were all satisfactory. A search of the literature revealed only 2 reports with follow-up results for more than 10 years. ${ }^{12,13}$ Baykut and associates ${ }^{12}$ reported low levels of valve-related complications at $1.1 \% / \mathrm{pt}-\mathrm{y}$ for thromboembolic events, $0.5 \% / \mathrm{pt}$-y for bleeding events, $0.6 \% / \mathrm{pt}$-y for $\mathrm{PVL}$, and $0.04 \%$ /pt-y for valve thrombosis, with a mean follow-up period of $4.3 \pm 2.5$ years (longest 11 years). Stefanidis and colleagues ${ }^{13}$ reported 3 cases of thromboembolic events as the only valve-related complications at a rate of 0.45 /pt-y, with a mean follow-up period of $48 \pm 38$ months (longest 119 months). There were no other valve-related complications, and the overall results were very favorable. In terms of postoperative anticoagulant therapy, patients with AVRs with sinus rhythm require a lower range of international normalized ratio than normal, at 1.5 to 2.5 according to Westaby, ${ }^{1}$ Van Nooten, ${ }^{14}$ and their associates. Both groups reported no problems with thromboembolic events. In this study, patients in sinus rhythm after AVR were maintained at an international normalized ratio of 1.6 to 2.0 , considerably lower than the international standard. Not only was the rate of bleeding events low at $0.19 \% / \mathrm{pt}-\mathrm{y}$, but the rate of thromboembolic events was also low at $0.44 \% / \mathrm{pt}-\mathrm{y}$ when compared with results for conventional mechanical valves. The reason for the low level of thromboembolic events with ATS valves appears to be related to the structural advantage of reduction of blood stagnation, with the open pivot inhibiting thrombosis.

We previously compared the results for the SJM, ATS, and Starr-Edwards ball valves retrospectively in patients who underwent MVR over the past 40 years at our hospital. We found that thromboembolic events showed no 
differences among the valves, but the overall incidence of valve-related complications was $2.99 \% / \mathrm{pt}$-y for the Starr-Edwards valve, $1.81 \% / p t-y$ for the SJM valve, and $0.77 \% / p t-y$ for the ATS valve, which was a significant difference. The ATS valve also showed good performance, as did the SJM valve. However, this was not a randomized controlled trial and there were differences in the chronological characteristics of the groups. In the future, a randomized controlled trial for comparison of each valve should be done.

Echocardiographic functional assessment of the ATS valve shows low pressure gradients, other than for the 16$\mathrm{mm}$ AP and 19-mm models, and otherwise satisfactory results. The patient who required a 16-mm AP prosthesis had a small annulus. She was an 83-year-old woman who originally underwent an aortic root enlargement and then had a valve replacement. Because her preoperative New York Heart Association classification was grade IV and her cardiac function was poor, aortic root enlargement was not performed to shorten the operating time and a $16-\mathrm{mm}$ AP prosthesis was selected. Moderate PPM was observed postoperatively, but her New York Heart Association classification improved to grade I, and there were no clinical problems. Use of 16-mm AP prostheses is limited. Severe PPM occurs more often at 19-mm than other sizes, and when moderate PPM is added, this size accounts for $83.3 \%$ of cases of PPM. The AP series showed the same prosthetic valve function as the 3-mm size standard series. Aoyagi and associates ${ }^{15}$ evaluated the opening angles of various sizes of ATS valves, reporting that $19-\mathrm{mm}$ prostheses had a significantly smaller opening angle than other sizes. Jazayeri and colleagues ${ }^{16}$ evaluated the AP series using Doppler echocardiography. The peak pressure gradient was $23.5 \pm 5.3 \mathrm{~mm}$ $\mathrm{Hg}$ for the $18-\mathrm{mm}$ AP size, $21.43 \pm 4.18 \mathrm{~mm} \mathrm{Hg}$ for the 20-mm AP, $18.67 \pm 8.31 \mathrm{~mm} \mathrm{Hg}$ for the 22-mm AP, and $15.14 \pm 5.59 \mathrm{~mm} \mathrm{Hg}$ for the 24-mm AP. The AP series are supra-annular prosthetic valves that use the same housing as the standard series. Valves in the AP series have the same orifice area as the 3-mm standard series because their design means that the circumferential reinforced ring and cuff are placed on the annulus. This is an excellent design for small aortic annulus.

These results are basically in agreement with those obtained in this study, and we consider the prosthetic valve function of the AP series to be excellent. For the AP series, a prosthesis no smaller than $18 \mathrm{~mm}$, and for the standard series, no smaller than $21 \mathrm{~mm}$, should be used wherever possible. If a smaller size is used, an aortic root enlargement should be considered.

Westaby and colleagues ${ }^{1}$ reported that postoperative LDH levels were 500 IU or less (normal range: 230-460 IU) in all patients. Shiono and coworkers ${ }^{17}$ reported that LDH decreased at an earlier stage with ATS valves than with SJM valves and normalized in patients with single valve replacements. In this study, normalization occurred in $63.6 \%$ of patients after AVR and $41.8 \%$ after MVR. After DVR, LDH levels were within the normal range in $7.1 \%$ of patients, representing excellent results in terms of hemolysis. The reasons for these results appear to be the absence of struts, as found in SJM valves, and elimination of turbulence in the pivot by using an open rather than closed pivot.

In patients undergoing valve replacement with mechanical valves, dissatisfaction often arises due not only to prosthetic valve-related complications, but also prosthetic valve noise. This is a very important factor in terms of QOL, although few studies have addressed this topic. In our hospital, we interviewed patients to evaluate their perceptions of prosthetic valve noise. The noise index is an "indicator of patient stress caused by prosthetic valve noise" proposed by the authors. It serves as an index for evaluation of the QOL of patients with prosthetic valve replacements using mechanical valves. ${ }^{10,18}$ In the present study, $92.8 \%$ of patients were not aware of prosthetic valve noise, representing an excellent result in terms of QOL. In an earlier study, we measured ATS prosthetic valve noise using interviews and high-sensitivity microphones, comparing it with the SJM valve. The results of the interviews and the sound pressure levels showed that the ATS valves are significantly quieter than SJM valves. In terms of frequency characteristics, ATS valve noise reaches a peak at about $1.2 \mathrm{kHz}$, and the power decreases as the frequency increases. The SJM valve also reaches a peak at about $1.2 \mathrm{kHz}$, and the power decreases as the frequency increases, but to a lesser degree that with the ATS valve. Strong components have been found in the 2- to $5-\mathrm{kHz}$ frequency range in which humans show the greatest sensitivity, and this has an effect on whether patients are aware of their prosthetic valve or not. ${ }^{10}$ Heart rate and the opening angle also affect perceptions of prosthetic valve noise. ${ }^{18}$ ATS valves have been reported to have smaller opening angles than SJM valves, ${ }^{19}$ a result confirmed at this hospital. ${ }^{18,20}$ In this study, cinefluoroscopy was not performed in all patients. Among the 50 MVR patients reported previously by the authors, only $7(14 \%)$ patients showed complete $85^{\circ}$ opening, whereas there was $80^{\circ}$ or more opening in $23(46 \%)$ patients and less than $80^{\circ}$ in $27(54 \%)$ patients. When we evaluated whether the lack of complete opening to an angle of $85^{\circ}$ had an adverse effect on prosthetic valve function by using transthoracic echocardiography, we found that the angle had no effect on prosthetic valve function. ${ }^{20}$ With a small opening angle, the low stress when there is impact on the valve may cause patients to be unaware of valve noise. The fact that there is not complete opening at an opening angle of $85^{\circ}$ has an adverse effect on the hemodynamics and prosthetic valve function, and problems arise if this leads to an increase in valve-related complications. However, the follow-up results in this study were entirely favorable, and there appeared to be no problems. In the future, we would like to clarify whether the lack of complete opening 
is a structural problem and whether the ATS valve is appropriate for use in all patient types.

\section{CONCLUSION}

This study revealed that the ATS valve showed no major problems during long-term follow-up. There were few valve-related complications and echocardiography showed good valve function.

Prosthetic valve noise is low, and this appears to be an excellent mechanical valve from the QOL standpoint. The ATS valve also has an excellent safety profile compared with other mechanical valves.

\section{References}

1. Westaby S, Van Nooten G, Sharif H, Pillai R, Caes F. Valve replacement with the ATS open pivot bileaflet prosthesis. Eur J Cardiothorac Surg. 1996;10:660-5.

2. Emery RW, Van Nooten GJ, Tesar PJ. for the Investigators for the ATS Clinical Open Pivot Heart Valve Food and Drug Administration Study The initial experience with the ATS medical mechanical cardiac valve prosthesis. Ann Thorac Surg. 2003;75:444-52.

3. Ikonomidis JS, Kratz JM, Crumbley AJ, Stroud MR, Bradley SM, Sade RM, et al. Twenty-year experience with the St Jude Medical mechanical valve prosthesis. J Thorac Cardiovasc Surg. 2003;126:2022-31.

4. Emery RW, Krough CC, Arom KV, Emery AM, Benyo-Albrecht K, Joyce LD, et al. The St. Jude Medical cardiac valve prosthesis: a 25-year experience with single valve replacement. Ann Thorac Surg. 2005;79:776-83.

5. Bryan AJ, Rogers CA, Bayliss K, Wild J, Angelini GD. Prospective randomized comparison of CarboMedics and St Jude Medical bileaflet mechanical heart valve prostheses: ten-year follow-up. J Thorac Cardiovasc Surg. 2007;133:614-22.

6. Sezai Y: Experience with the St. Jude Medical prosthesis. In: DeBakey ME, ed. Advances in cardiac valves: clinical perspectives. New York: Yorke Medical Books; 1983:88-102.

7. Sezai A, Shiono M, Hata M, Iida M, Negishi N, Sezai Y. 40 years experience in mitral valve replacement using Starr-Edwards, St. Jude Medical and ATS valves. Ann Thorac Cardiovasc Surg. 2006;12:249-56.
8. Kratz JM, Crawford FA, Sade RM, Crumbley AJ, StroudSt MR. Jude prosthesis for aortic and mitral valve replacement: a ten-year experience. Ann Thorac Surg. 1993;56:462-8.

9. Zellner JL, Kratz JM, Crumbley AJ, Stroud MR, Bradley SM, Sade RM, et al. Long-term experience with the St. Jude Medical valve prosthesis. Ann Thorac Surg. 1999;68:1210-8.

10. Sezai A, Shino M, Orime Y, Hata H, Yagi S, Negishi N, et al. Evaluation of valve sound and its effects on ATS prosthetic valves in patients' quality of life. Ann Thorac Surg. 2000;69:507-12.

11. Akins CW, Miller DC, Turina MI, Kouchoukos NT, Blackstone EH, Grunkemeier GL, et al. Guidelines for reporting mortality and morbidity after cardiac valve interventions. J Thorac Cardiovasc Surg. 2008;135:732-8.

12. Baykut D, Grize L, Schindler C, Keil AS, Bernet F, Zerkowski H. Eleven-year single-center experience with the ATS open pivot bileaflet heart valve. Ann Thorac Surg. 2006;82:847-52.

13. Stefanidis C, Nana AM, De Canniere D, Antoine M, Jansens J, Huynh C, et al. 10year experience with the ATS mechanical valve in the mitral position. Ann Thorac Surg. 2005;79:1934-8.

14. Van Nooten G, Case F, Francois K, Missault L, Van Belleghem Y. Clinical experience with the first 100 ATS heart valve implants. Cardiovasc Surg. 1996;4: 288-92.

15. Aoyagi S, Arinaga K, Fukunaga S, Tayama E, Kosuga T, Akashi H. Leaflet movement of the ATS valve in the aortic position: unique behavior observed in 19-mm valves. Ann Thorac Surg. 2006;82:853-7.

16. Jazayeri S, Gomez MC, Tatou E, Ecarnot A, Saleh M, Bouchot O, et al. Clinical experience and Doppler echocardiographic assessment of the first one hundred ATS AP (advanced performance) prosthetic valve in the aortic position. $J$ Heart Valve Dis. 2003;12:628-34.

17. Shiono M, Sezai Y, Sezai A, Omoto R, Kyo S, Hatanaka M, et al. Multi-institutional experience of the ATS open pivot bileaflet valve in Japan. Ann Thorac Cardiovasc Surg. 1996;2:51-8.

18. Umeda T. An evaluation study on the quietness of the ATS valve. Ann Thorac Cardiovasc Surg. 2007;13:172-7.

19. Aoyagi S, Kawara T, Fukunaga S, Mizoguchi T, Nishi Y, Kawano H, et al. Cineradiographic evaluation of ATS open pivot bileaflet valves. J Heart Valve Dis. 1997;6:258-63.

20. Sezai A, Umeda T, Hata M, Niino T, Unosawa S, Tokai K, et al. A transesophageal echocardiographic and cine-fluoroscopic evaluation of an ATS prosthetic valve opening. Surg Today. 2009;39:300-5. 